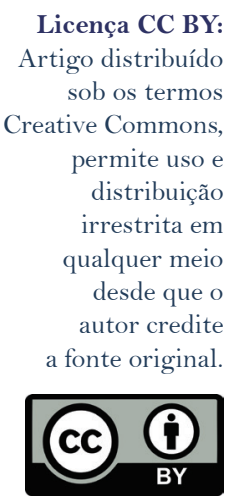

\section{ANÁLISE DO NÍVEL DE SUSTENTABILIDADE DA REDE HOTELEIRA DE FOZ DO IGUAÇU - PR}

\author{
ANALYSIS OF THE SUSTAINABILITY LEVEL OF THE HOTEL \\ NETWORK OF FOZ DO IGUAÇU - PR
}

\author{
ANÁLISIS DEL NIVEL DE SUSTENTABILIDAD DE LA RED \\ HOTELERA DE FOZ DO IGUAÇU - PR
}

JÚLIO CÉSAR FERREIRA'

Universidade do Vale do Rio dos Sinos, São Leopoldo, Rio Grande do Sul, Brasil

GEYSLER ROGIS FLOR BERTOLINI ${ }^{2}$

Universidade Estadual do Oeste do Paraná, Cascavel, Paraná, Brasil

LORENI TERESINHA BRANDALISE ${ }^{3}$

Universidade Estadual do Oeste do Paraná, Cascavel, Paraná, Brasil

\begin{abstract}
RESUMO: A sustentabilidade tem sido questão relevante para os meios de hospedagem. A adesão à sustentabilidade na gestão hoteleira pode ser considerada como um vetor, capaz de gerar ganhos de ordem econômicos, sociais e ambientais para os negócios e para a sociedade em geral. Este artigo tem por objetivo analisar o nível de gestão da sustentabilidade dos hotéis de Foz do Iguaçu, Paraná. Para tanto, foram selecionados os 23 hotéis associados à Associação Brasileira da Indústria de Hotéis (ABIH) para compor a amostra. Foi empregado para análise o modelo (GSE) Grid de Sustentabilidade Empresarial. A pesquisa caracterizou-se, quanto aos objetivos, como exploratória e descritiva e, quanto aos procedimentos técnicos, classificou-se em bibliográfica e de levantamento. Os resultados apontaram que a maioria dos hotéis investigados não apresentam desempenhos sustentáveis satisfatórios nas três dimensões. A pesquisa contribuiu com importantes informações sobre o perfil da gestão hoteleira, tanto para o desenvolvimento sustentável nos aspectos ambiental, econômico e social, quanto para a eficiência na gestão de seus empreendimentos em busca da Sustentabilidade Empresarial.
\end{abstract}

PALAVRAS-CHAVE: Hotelaria. Desenvolvimento Sustentável. Sustentabilidade Empresarial. 
ABSTRACT: Sustainability is an important issue for accommodation establishments. Adherence to sustainability in hotel management can be considered a policy that is capable of generating economic, social and environmental gains for the business and for society in general. This article aims to analyze the level of sustainability management of hotels in Foz do Iguaçu, Paraná. For this purpose, 23 member hotels of the Brazilian Hotel Industry Association $(\mathrm{ABIH})$ were selected to make up the sample. For the analysis, the Corporate Sustainability Grid (CSG) was used. In terms of objectives, this study is characterized as exploratory and descriptive, and in relation to the technical procedures, it is classified as bibliographical and survey. The results showed that most of the hotels investigated do not present satisfactory sustainable performances in the three dimensions. The research contributes important information on the profile of hotel management, both for sustainable development in the environmental, economic and social aspects, and for efficiency in the management of their enterprises, in search of Corporate Sustainability.

KEYWORDS: Hotel management. Sustainable development. Corporate Sustainability.

RESUMEN: La sustentabilidad ha sido cuestión relevante para los medios de hospedaje. La adhesión a la sustentabilidad en la gestión hotelera puede ser considerada como un vector, capaz de generar ganancias económicas, sociales y ambientales para los negocios y para la sociedad en general. Este artículo tiene por objetivo analizar el nivel de gestión de la sustentabilidad de los hoteles de Foz do Iguaçu, Paraná. Para tanto, fueron seleccionados los 23 hoteles asociados a la Asociación Brasileña de la Industria de Hoteles (ABIH) para componer la muestra. Fue empleado para el análisis el modelo (GSE) Grid de Sustentabilidad Empresarial. La investigación se caracterizó, tanto a los objetivos, como exploratoria y descriptiva y, tanto a los procedimientos técnicos, se clasificó en bibliográfica y de levantamiento. Los resultados apuntaron que la mayoría de los hoteles investigados no presentan desempeños sostenibles satisfactorios en las tres dimensiones. La investigación contribuyó con importantes informaciones sobre el perfil de la gestión hotelera, tanto para el desarrollo sostenible en los aspectos ambientales, económicos y sociales, como para la eficiencia en la gestión de sus emprendimientos en búsqueda de la Sustentabilidad Empresarial.

PALABRAS-CLAVE: Hotelería. Desarrollo Sostenible. Sustentabilidad Empresarial.

\section{INTRODUÇÃO}

A análise e o estudo da sustentabilidade relacionados com a atividade turística vislumbram uma dimensão determinante para o turismo atual e futuro, que deve ser utilizado como um fator de desenvolvimento e implementação de boas práticas sustentáveis, além da criação de novas práticas de gestão que proporcionem um arranjo harmônico no desenvolvimento econômico, ambiental e social das organizações.

Os programas de gestão ambiental para meios de hospedagem são o início do processo, que busca a sustentabilidade de destinos turísticos, uma vez que a hotelaria representa o maior setor dentro da economia turística, portanto deve ser vista como peça chave no processo de gestão sustentável dos destinos turísticos (Dias \& Pimenta, 2005).

Para Andrade (2012), é extremamente relevante a tomada de decisão na organização com base na gestão ambiental, econômica e social, pois assim o gestor buscará a consecução e a continuidade da organização, de forma a apresentar um equilíbrio sistêmico entre o governo, as empresas e a sociedade.

Por meio de estudos, pode-se observar que o setor hoteleiro nutre estreita relação com o desenvolvimento de práticas comprometidas com a sustentabilidade. A gestão 
ambiental nas organizações hoteleiras está ligada à necessidade de melhorar a qualidade da oferta de serviços devido à demanda dos clientes. Dessa forma, empresas hoteleiras estão sendo estimuladas pela gestão dos custos, pressão da comunidade e governo, expectativas dos consumidores e cenário competitivo para tornar a sustentabilidade uma prioridade e assim a sustentabilidade torna-se, então, questão relevante para o turismo e hotelaria neste século, por uma demanda mais sensível às questões inerentes ao crescimento econômico em equilíbrio com o desenvolvimento social e ambiental (Reynolds, 2013; Morais Neto; Pereira; Macari, 2012; Barreto et al., 2014).

Nesse contexto, a presente pesquisa foi guiada pelo seguinte questionamento: qual o nível de sustentabilidade dos hotéis de Foz do Iguaçu, utilizando o modelo de mensuração Grid de Sustentabilidade Empresarial (GSE)? Desta forma, o objetivo deste trabalho é analisar o nível de sustentabilidade dos hotéis da rede hoteleira de Foz do Iguaçu - PR. A fim de atender esse objetivo principal, foi necessário atender aos seguintes objetivos secundários: caracterizar a importância da sustentabilidade na gestão da rede hoteleira; discutir e apresentar a aplicabilidade dos modelos teóricos dos indicadores de sustentabilidade; e mensurar o nível de sustentabilidade das empresas da rede hoteleira de Foz do Iguaçu - PR por meio do modelo de Grid de Sustentabilidade Empresarial (GSE).

O tema da pesquisa é relevante por contribuir com o fornecimento de dados para estabelecer o panorama atual, no que diz respeito à importância atribuída pelos gestores, ao uso de práticas de sustentabilidade nos meios de hospedagem.

Para atingir o objetivo proposto, o artigo foi estruturado em cinco capítulos: Introdução; Referencial Teórico; Métodos e Procedimentos da Pesquisa; Análise dos Resultados e por último as Considerações Finais, seguido das referências utilizadas para a realização do estudo.

\section{MARCO TEÓRICO}

\section{DesenVolvimento SustentáVEL}

O conceito de desenvolvimento sustentável foi proposto pela Comissão Mundial sobre o Meio Ambiente e Desenvolvimento no relatório Our Commom Future (Nosso Futuro Comum) ou Relatório Brundtland (BM\&FBOVESPA, 2016). Neste documento, de 1987, considera-se sustentável o desenvolvimento que satisfaz as necessidades presentes sem comprometer a capacidade das gerações futuras de suprir suas próprias necessidades.

Em 2015, um pacto global capitaneado pela ONU estabeleceu os objetivos do desenvolvimento sustentável com metas para 2030. Entre estes se encontram: 1) Erradicação da pobreza; 2) Fome zero e agricultura sustentável; 3) Saúde e bem-estar; 4) Educação de qualidade; 5) Igualdade de gênero; 6) Água potável e saneamento; 7) Energia acessível e limpa; 8) Trabalho decente e crescimento econômico; 9) Indústria, inovação e infraestrutura; 10) Redução das desigualdades; 11) Cidades e comunidades sustentáveis; 12) Consumo e produção responsáveis; 13) Ação contra a mudança global do clima; 14) Vida na água; 15) Vida terrestre; 16) Paz, justiça e instituições eficazes; e 17) Parcerias e meios de implementação (PNUD, 2016b). 
Normas de certificação, como a ABNT NBR 15401, podem ser vetores importantes a seguir, pois seus objetivos buscam especificar requisitos relativos à sustentabilidade dos meios de hospedagem, mediante critérios de desempenho e permitir a formulação de uma política de sustentabilidade que considere os requisitos legais, atenda aos princípios do turismo sustentável e propicie informações referentes aos impactos ambientais, socioculturais e econômicos significativos para todas as partes interessadas (ABNT, 2014).

A ABNT publicou, em 20 de maio, a norma ABNT NBR 15401:2014 - Meios de hospedagem - Sistema de gestão da sustentabilidade - Requisitos, que revisa a norma ABNT NBR 15401:2006, elaborada pelo Comitê Brasileiro de Turismo (ABNT/CB-54). Esta norma especifica os requisitos relativos à sustentabilidade de meios de hospedagem, estabelecendo critérios mínimos específicos de desempenho em relação à sustentabilidade e permitindo que um meio de hospedagem formule uma política e objetivos que levem em conta os requisitos legais e as informações referentes aos impactos ambientais, socioculturais e econômicos significativos (ABNT, 2014).

Para Araújo e Mendonça (2009), a evolução do pensamento sustentável, que parte da esfera pública, cabendo a cada nação promover o desenvolvimento sustentável em seu território, chega às organizações privadas, resultando em clientes mais exigentes que demandam uma posição mais responsável das empresas. Nesse enredo, emerge o conceito de sustentabilidade empresarial, composta de ações que procuram visar à redução de impactos ambientais e à promoção de programas sociais, mantendo-se economicamente viável no mercado.

Nesse sentido, deverá ocorrer a alocação da perspectiva sustentável no planejamento estratégico e na adequação da estrutura para tal posicionamento. Butler, Coccossis e Mexa (2004) apontam que o planejamento deve ser feito dentro dos princípios da durabilidade de um destino turístico. O modelo auxilia os gestores a manter o desenvolvimento do destino turístico dentro de limites ambientais e sociais, a partir da ênfase na comunidade e do respeito ao meio ambiente por meio de regulação e observação da capacidade de carga dos atrativos turísticos.

A ideia central desse modelo é a possibilidade de identificar o estágio de desenvolvimento de um determinado destino. Nesse princípio, seria uma decisão estratégica a ser tomada para diferentes estágios de desenvolvimento do local, que podem ser: exploração, envolvimento, desenvolvimento, consolidação, estagnação e pós-estagnação (Butler, Coccossis \& Mexa, 2004).

A partir dos pressupostos da sustentabilidade como variável contingenciadora, as atividades turísticas passam a ser questionadas pela forma que estão sendo conduzidas e o ambiente externo exerce uma influência para que tais pressupostos sejam de fato aplicados (Ruscheinsky, 2004). Em longo prazo, segundo Oliveira (2005), as empresas que trabalham com atividades turísticas irão ajustar suas ações para que não percam em desempenho e em vantagem competitiva, promovendo, inclusive, a inovação no setor. Vendo essa movimentação, muitas empresas já se engajam e modificam suas estruturas para recepcionar um cliente mais envolvido com a sustentabilidade. 


\section{DIMENSÕES DA SUSTENTABILIDADE}

O conceito de sustentabilidade foi enunciado por John Elkington ao fundar a consultoria Sustain Ability em 1987, pouco antes da divulgação do Relatório Brundtland (1985). Esse conceito foi ampliado para um modelo de mudança social que ficou conhecido como o "Triple Bottom Line" ou "Tripé da Sustentabilidade" - integração entre as dimensões econômica, social e ambiental -, seguido dos termos "People, Planet, Profit" ou "Pessoas, Planeta e Lucro".

A dimensão econômica admite que as diversidades das atividades de produção, em todo o seu processo, apresentem um equilíbrio intersetorial no desenvolvimento econômico (Oliveira, 2005). A viabilidade econômica do negócio, para Azapagic (2003), é componente central do desenvolvimento sustentável, pois, por meio do lucro são gerados empregos, através dos quais é proporcionada à sociedade a possibilidade de alcançar melhores condições de vida. Para Lorenzetti, Cruz e Ricioli (2008), refere-se ao impacto das organizações sobre as condições econômicas das partes interessadas e sobre o sistema econômico em todos os níveis, ou seja, representa a geração de riqueza pela e para a sociedade pelo fornecimento de bens e serviços.

O pilar ambiental, para Krajnc c e Glavic (2005), contempla a conservação e o manejo dos recursos naturais. Para isso, é necessário que a empresa, sob a perspectiva dos impactos de suas operações e produtos sobre os sistemas naturais vivos e não vivos, procure minimizar os impactos negativos e amplificar os positivos, tanto em processos de entrada quanto de saída.

De acordo com o pensamento de Lorenzetti, Cruz e Ricioli (2008), o pilar social se refere ao alcance da igualdade e à participação de todos os grupos sociais na construção e na manutenção do equilíbrio do sistema, compartilhando direitos e responsabilidades. Para as empresas, a dimensão social refere-se ao seu impacto no sistema social em que operam. Assim, o desempenho social é abordado por meio desta análise sobre as partes interessadas em nível local, nacional e global.

A sustentabilidade social pode ser compreendida como a instauração de um processo que se desenvolve guiado pela visão da boa sociedade, com o objetivo de promover a igualdade entre as pessoas, melhorando a distribuição da renda, os direitos e a condição de vida e, assim, conseguir reduzir as diferenças entre ricos e pobres (Mendes, 2009).

Sob a ótica das organizações, a sustentabilidade social refere-se às atitudes empresariais em relação aos próprios colaboradores, fornecedores, contratados e consumidores, além de impactos na sociedade em geral, para além de seus domínios (Krajnc \& Glavic, 2005).

Os três pilares da sustentabilidade, para Callado (2010), devem interagir. Assim sendo, é possível inferir que uma visão equilibrada a respeito de como fazer uso dos recursos que a natureza oferece é essencial para se garantir às gerações futuras uma sociedade de prosperidade e justiça, melhor saúde ambiental e melhor qualidade de vida. No encadeamento do tema, este estudo abarcará as três dimensões da sustentabilidade. 


\section{SUSTENTABILIDADE NA HOTELARIA}

A discussão da sustentabilidade se consolida como um dos temas centrais no debate do turismo como fenômeno complexo. Segundo, De Azevedo et al. (2006), o turismo, interpretado como a atividade econômica que mais cresce no mundo, passa gradualmente a incorporar novos olhares de planejamento, como resultado de seu potencial gerador de emprego e renda, aporte de benefícios econômicos, sociais e ambientais e mecanismo para inclusão e transformação social, num sentido mais amplo em termos da reflexão ética que implica.

O turismo sustentável definido pela Organização Mundial de Turismo (OMT, 2003, p. 24) é aquele que "atende às necessidades dos turistas de hoje e das regiões receptoras, ao mesmo tempo em que protege e amplia as oportunidades para o futuro". Assim, busca atender às atuais necessidades econômicas, sociais e de qualidade de vida para o desenvolvimento regional, enquanto conserva os recursos naturais e mantém a integridade cultural da população local, promovendo a responsabilidade coletiva e a satisfação das expectativas dos turistas de maneira que a atividade possa continuar indefinidamente, proporcionando os benefícios propostos.

Os consumidores estão mais sensíveis às preocupações com a sustentabilidade, segundo Serpa e Fourneau (2007), razão pela qual o setor hoteleiro abrange investimentos em medidas sustentáveis e busca por certificações ambientais e selos de qualidade, aponta Coelho (2009).

Por outro lado, persiste certo grau de dificuldade para que medidas de sustentabilidade e responsabilidade social corporativa sejam visíveis e aplicáveis ao consumidor final. Além disso, implementar serviços sustentáveis no mercado ainda é um desafio para empresas de qualquer setor, inclusive o turístico (Coelho, Gosling \& Gonçalves 2013).

O tema gestão da sustentabilidade na hotelaria, segundo Peres Junior e Rezende (2011), tem sido objeto de estudos em várias partes do mundo: na Espanha (Gil, Gimenez \& Lorente, 2001); na Turquia (Tosun, 2001); na China (Chan, 2005); na Suécia e na Polônia (Bohdanowicz, 2006); no Vietnã (Le, Hollenhorst, Harris, McLaughlin, \& Shook, 2006); na Tailândia (Henderson, 2007; Erdogan \& Baris, 2007; Molina, Cortés, Moliner, \& Tarí, 2009), dentre vários outros.

A partir dos resultados do estudo que incluiu 367 gerentes de hotéis ecológicos em Taiwan (Horng et al., 2017), pode-se afirmar que a inovação sustentável é um atributo crítico na gestão moderna de hotéis, amplamente reconhecido por especialistas e gerentes de hotéis. Assim, é fundamental que as práticas orientadas para sustentabilidade visem, além da vantagem competitiva, à redução do impacto que gera no meio ambiente e na sociedade, criando valor por meio da reformulação dos hotéis.

O estudo de Rosalind \& Karanikola (2014), realizado no setor hoteleiro de Dubai, Emirados Árabes Unidos, aponta que as empresas hoteleiras se comprometem com a sustentabilidade ambiental devido ao impacto que os hotéis têm sobre o meio ambiente e considerando os benefícios que podem advir do fato de serem ecologicamente corretos, como imagem corporativa positiva e conscientização das partes interessadas sobre políticas, práticas e iniciativas da empresa. 
Prud'homme e Raymond (2016) demonstraram em sua pesquisa, realizada em hotéis do Canadá, que a adoção de práticas orientadas para sustentabilidade hoteleira é motivada pela pressão dos consumidores, das certificações, da proteção ao meio ambiente e das questões relacionadas à gestão de custos.

Barber (2014) enfatiza em sua pesquisa em hotéis norte-americanos que o processo de incorporação de ações que buscam atender a sustentabilidade, por meio da gestão ambiental e responsabilidade social, pode gerar vantagem competitiva à empresa hoteleira e, ainda, é fundamental a comunicação como transparência da implementação dessas práticas orientadas para sustentabilidade.

Os estudos de Rosa e Silva (2017) demonstram que o tema de sustentabilidade ambiental é relevante e atual. A sustentabilidade ambiental, portanto, pode ser observada tanto no âmbito organizacional quanto no âmbito político e econômico, permitindo à academia explorar diversos temas relacionados ao meio ambiente e à sociedade dentro do contexto hoteleiro, visando observar impactos econômicos, sociais e ambientais da atividade, bem como buscar contribuir com um tema de preocupação global: meio ambiente.

\section{INDICADORES DE SUSTENTABILIDADE}

Os indicadores de sustentabilidade, inicialmente, podem ser tratados como um instrumento utilizado para monitorar o desenvolvimento sustentável, os quais são responsáveis por capturar tendências para informar os agentes de decisão, orientar o desenvolvimento e o monitoramento de políticas e estratégias.

Callado (2010, p. 39) conceitua indicadores como "ferramentas centrais por permitirem um acompanhamento das principais variáveis de interesse da empresa e por possibilitarem o planejamento de ações objetivando as melhorias de desempenho".

A operacionalização do modelo Grid de Sustentabilidade Empresarial (GSE) é realizada a partir do desenvolvimento das seguintes etapas: cálculo de Escores Parciais de Sustentabilidade (EPS); cálculo do Escore de Sustentabilidade Empresarial (ESE); e integração dos EPS por meio de localização de empresa(s) no Grid de Sustentabilidade Empresarial (GSE) (Callado, 2010, p. 80).

A partir da aplicação deste modelo, os resultados obtidos poderão servir de suporte aos processos decisórios dos gestores, direcionados ao desenvolvimento sustentável por conseguir visualizar melhor seus gastos e o consumo de recursos naturais. Ele permite, por meio de etapas, avaliar e mensurar os desempenhos das empresas a partir dos Escores Parciais de Sustentabilidade (EPS).

Desse modo, pelo fato de o modelo GSE ter sido validado no estudo de Callado (2010) e posteriormente aplicado nas pesquisas de Andrade \& Câmara (2012) e da Costa Sousa et al. (2013), que abordaram especificamente a avaliação da sustentabilidade nos meios de hospedagem, optou-se por utilizar o modelo GSE para análise da sustentabilidade, dada a especificidade desta pesquisa. 


\section{METODOLOGIA}

A presente pesquisa apresenta características de cunho descritivo, pois, segundo Boaventura (2007), é aquela que identifica as características de um fenômeno por meio da pesquisa. Quanto aos seus objetivos, pode ser classificada como exploratória descritiva. Segundo Gil (2008), a pesquisa exploratória objetiva gera maior familiaridade com o problema enquanto que a descritiva objetiva descreve as características de determinada população.

Quanto aos procedimentos técnicos que permitem o delineamento da investigação empírica, são divididos em dois grupos: "aqueles que se valem de fontes de papel" e "aqueles cujos dados são fornecidos por pessoas" (Gil, 2008, p. 50). Integram o primeiro grupo a pesquisa bibliográfica e documental e, no segundo grupo, a pesquisa experimental, ex-post-facto, levantamento de campo ou survey, estudo de caso, pesquisa-ação e pesquisa participante.

Quanto ao universo da pesquisa, compreende os 113 hotéis de Foz do Iguaçu PR. Desse universo estabeleceram-se como critério da amostra hotéis credenciados à Associação Brasileira de Hotéis $(\mathrm{ABIH})$ e, dessa maneira, a composição totalizou 23 hotéis. O instrumento utilizado para o levantamento dos dados foi o questionário, o qual buscou avaliar a Sustentabilidade Empresarial dos aspectos ambientais, econômicos e sociais, conforme as variáveis analisadas pelo modelo de mensuração proposto por Callado (2010), considerando as três dimensões citadas, num total de 43 indicadores.

Para a concretização do método proposto, foram seguidas as etapas propostas por Callado (2010, p. 81): (1) cálculo de Escores Parciais de Sustentabilidade (EPS); (2) cálculo de Escore de Sustentabilidade Empresarial (ESE); (3) integração de Escores Parciais de Sustentabilidade por meio da localização de empresas no GSE. O tratamento dos dados foi realizado de acordo com a forma original utilizada pelo autor do GSE (Callado, 2010, p. 79).

\section{Cálculo dos Escores Parciais de Sustentabilidade (EPS)}

O modelo proposto por Callado (2010) mensura o desempenho empresarial por meio da aplicação da Equação 1.

\section{Desempenho da empresa $=\sum_{i=1}^{n} W i P i$}

Onde:

wi $=$ peso definido pelos especialistas ao indicador de desempenho i;

pi = nível de desempenho apresentado pela empresa no indicador i;

$\mathrm{n}=$ número de indicadores considerados.

O modelo GSE, idealizado por Callado (2010), partiu de cinco modelos de mensuração de sustentabilidade empresarial, dos quais foram coletados 435 indicadores, distribuídos nas dimensões ambiental, econômica e social. Todos os indicadores passaram por um processo de avaliação por parte de 10 especialistas da área quanto à relevância e ao grau de importância. 
Após uma triagem, que excluiu os indicadores que continham a mesma finalidade e aqueles que haviam recebido menos de sete avaliações dos especialistas, chegou-se a 43 indicadores de sustentabilidade. Para o cálculo do desempenho de cada um dos 43 indicadores, foram utilizados, conforme demonstrado na Tabela 1, o valor atribuído para cada nível, sendo atribuído um para o Desempenho Inferior, dois para o Desempenho Intermediário e três para o Desempenho Superior.

Tabela 1: Dimensões e indicadores do Grid de Sustentabilidade Empresarial (GSE)

\begin{tabular}{|c|c|c|c|c|}
\hline \multicolumn{5}{|c|}{ DIMENSÃO AMBIENTAL } \\
\hline \multirow[b]{2}{*}{ Indicadores (Wi) } & \multirow{2}{*}{$\begin{array}{c}\text { Peso } \\
\text { atribuído } \\
\text { ao } \\
\text { indicador }\end{array}$} & \multicolumn{3}{|c|}{ CATEGORIAS DE RESULTADO } \\
\hline & & $\begin{array}{l}\text { Valor } \\
\text { Mínimo (p1) } \\
\times 1\end{array}$ & $\begin{array}{l}\text { Valor Médio } \\
\text { (p1) } \times 2\end{array}$ & $\begin{array}{l}\text { Valor } \\
\text { Máximo } \\
\text { (p1) } \times 3\end{array}$ \\
\hline Sistema de Gestão Ambiental (SGA) & 2,250 & 2,2500 & 4,5000 & 6,7500 \\
\hline Quantidade de água utilizada & 2,500 & 2,5000 & 5,0000 & 7,5000 \\
\hline Processos decorrentes de infrações & 2,250 & 2,2500 & 4,5000 & 6,7500 \\
\hline $\begin{array}{c}\text { Treinamento, educação e capacitação em } \\
\text { aspectos ambientais }\end{array}$ & 2,7500 & 2,7500 & 5,5000 & 8,2500 \\
\hline Economia de energia & 2,2500 & 2,2500 & 4,5000 & 6,7500 \\
\hline Desenvolvimento de tecnologias equilibradas & 2286 & 2,286 & 4,572 & 6,858 \\
\hline Ciclo de vida de produtos e serviços & 1,857 & 1,8570 & 3,7140 & 5,5710 \\
\hline $\begin{array}{l}\text { Quantidade de combustível fóssil utilizado por } \\
\text { ano }\end{array}$ & 2,000 & 2,0000 & 4,0000 & 6,0000 \\
\hline Reciclagem e utilização de água & 2,500 & 2,5000 & 5,0000 & 7,5000 \\
\hline Acidentes ambientais & 2,571 & 2,5710 & 5,1420 & 7,7130 \\
\hline Fontes de recursos utilizados & 2,000 & 2,0000 & 4,0000 & 6,0000 \\
\hline Redução de resíduos & 2,000 & 2,0000 & 4,0000 & 6,0000 \\
\hline Produção de resíduos tóxicos & 2,143 & 2,1430 & 4,2860 & 6,4290 \\
\hline ISO 14001 & 1,714 & 1,7140 & 3,4280 & 5,1420 \\
\hline Qualidade do solo & 2,286 & 2,2860 & 4,5720 & 6,8580 \\
\hline Qualidade de água de superfície & 2,286 & 2,2860 & 4,5720 & 6,8580 \\
\hline \multicolumn{5}{|c|}{ DIMENSÃO ECONÔMICA } \\
\hline \multirow[b]{2}{*}{ Indicadores (Wi) } & \multirow{2}{*}{$\begin{array}{c}\text { Peso } \\
\text { atribuído } \\
\text { ao } \\
\text { indicador }\end{array}$} & \multicolumn{3}{|c|}{ CATEGORIAS DE RESULTADO } \\
\hline & & $\begin{array}{c}\text { Valor } \\
\text { Mínimo (p1) } \\
\times 1\end{array}$ & $\begin{array}{l}\text { Valor Médio } \\
\text { (p1) } \times 2\end{array}$ & $\begin{array}{c}\text { Valor } \\
\text { Máximo } \\
(p 1) \times 3\end{array}$ \\
\hline Investimentos éticos & 2,500 & 2,5000 & 5,0000 & 7,5000 \\
\hline Gastos em saúde e em segurança & 2,000 & 2,0000 & 4,0000 & 6,0000 \\
\hline Investimentos em tecnologias limpas & 2,250 & 2,2500 & 4,5000 & 6,7500 \\
\hline Nível de endividamento & 1,857 & 1,8570 & 3,7140 & 5,5710 \\
\hline Lucratividade & 2,143 & 2,1430 & 4,2860 & 6,4290 \\
\hline Participação de mercado & 2,000 & 2,0000 & 4,0000 & 6,0000 \\
\hline Passivo ambiental & 2,000 & 2,0000 & 4,0000 & 6,0000 \\
\hline Gastos em proteção ambiental & 2,143 & 2,1430 & 4,2860 & 6,4290 \\
\hline Auditoria & 1,857 & 1,8570 & 3,7140 & 5,5710 \\
\hline Avaliação de resultados da organização & 2,286 & 2,2860 & 4,5720 & 6,8580 \\
\hline Volume de vendas & 2,000 & 2,0000 & 4,0000 & 6,0000 \\
\hline Gastos com benefícios & 2,000 & 2,0000 & 4,0000 & 6,0000 \\
\hline Retorno sobre capital investido & 2,143 & 2,1430 & 4,2860 & 6,4290 \\
\hline Selos de qualidade & 2,000 & 2,0000 & 4,0000 & 6,0000 \\
\hline \multicolumn{5}{|c|}{ DIMENSÃO SOCIAL } \\
\hline \multirow[b]{2}{*}{ Indicadores (Wi) } & \multirow{2}{*}{$\begin{array}{c}\text { Peso } \\
\text { atribuído } \\
\text { ao } \\
\text { indicador }\end{array}$} & \multicolumn{3}{|c|}{ CATEGORIAS DE RESULTADO } \\
\hline & & $\begin{array}{c}\text { Valor } \\
\text { Minimo (p1) } \\
\times 1\end{array}$ & $\begin{array}{l}\text { Valor Médio } \\
\text { (p1) } \times 2\end{array}$ & $\begin{array}{c}\text { Valor } \\
\text { Máximo } \\
(p 1) \times 3\end{array}$ \\
\hline Geração de trabalho e renda & 2,429 & 2,4290 & 4,8580 & 7,2870 \\
\hline Auxílio em educação e treinamento & 2,000 & 2,0000 & 4,0000 & 6,0000 \\
\hline Padrão de segurança de trabalho & 2,250 & 2,2500 & 4,5000 & 6,7500 \\
\hline Ética organizacional & 2,375 & 2,3750 & 4,7500 & 7,1250 \\
\hline Interação social & 2,250 & 2,2500 & 4,5000 & 6,7500 \\
\hline $\begin{array}{l}\text { Empregabilidade e gerenciamento de fim de } \\
\text { carreira }\end{array}$ & 1,750 & 1,7500 & 3,5000 & 5,2500 \\
\hline $\begin{array}{c}\text { Políticas de distribuição de lucros e resultados } \\
\text { entre funcionários }\end{array}$ & 2,429 & 2,4290 & 4,8580 & 7,2870 \\
\hline Conduta de padrão internacional & 1,714 & 1,7140 & 3,4280 & 5,1420 \\
\hline Capacitação e desenvolvimento de & 2,429 & 2,4290 & 4,8580 & 7,2870 \\
\hline Acidentes fatais & 2,571 & 2,5710 & 5,1420 & 7,7130 \\
\hline Contratos legais & 2,286 & 2,2860 & 4,5720 & 6,8580 \\
\hline Stress de trabalho & 2,143 & 2,1430 & 4,2860 & 6,4290 \\
\hline Segurança e produto & 1,857 & 1,8570 & 3,7140 & 5,5710 \\
\hline
\end{tabular}

Fonte: Callado (2010) 
Rev.Tur., Visão e Ação, v21, n2, p102-127, Mai./Ago. 2019 - Balneário Camboriú, Santa Catarina, Brasil

Para cada dimensão de sustentabilidade considerada, foram propostos intervalos de valores associados aos respectivos Escores Parciais de Sustentabilidade (EPS). Esses intervalos têm três pontos referenciais relevantes. São eles: Escore mínimo (Emín), Escore médio (Eméd) e Escore máximo (Emáx), sendo que as formas do cálculo estão demonstradas na Figura 1.

Figura 1: Equação dos escores

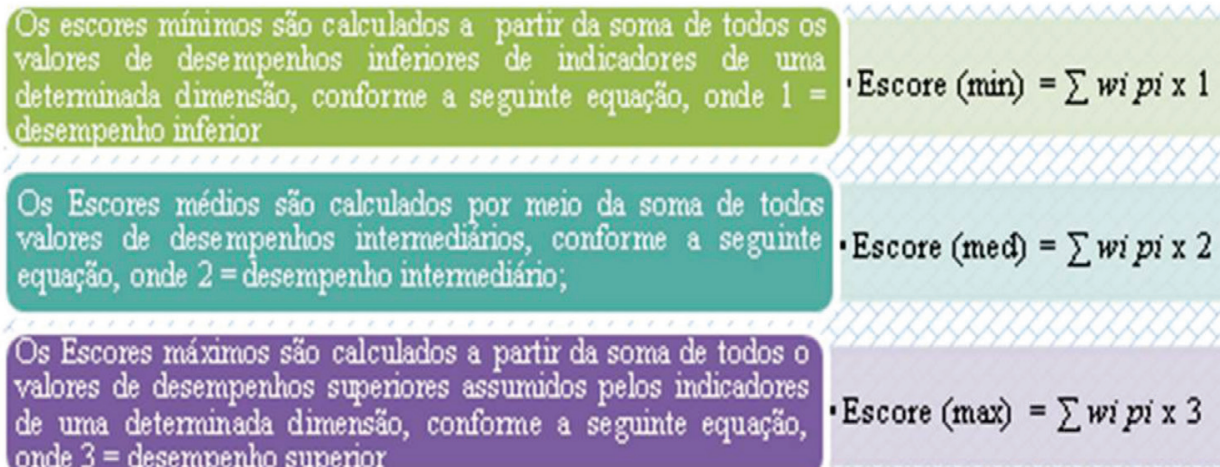

Fonte: Pol, Agostini, Frâncio, Pereira, \& Zanella (2011).

\section{CÁLCULO DE ESCORE DE SUSTENTABILIDADE EMPRESARIAL (ESE)}

Esses escores são calculados a partir da soma de todos os valores de cada nível de desempenho dos indicadores de determinada dimensão, conforme demonstra a Tabela 02, que apresenta os intervalos de valores de Escores Parciais de Sustentabilidade (EPS) das dimensões (ambiental, econômica e social) consideradas pelo GSE.

Tabela 02: Resultado de Escores Parciais de Sustentabilidade (EPS)

\begin{tabular}{|l|l|l|l|}
\hline \multirow{2}{*}{ DIMENSÃO } & \multicolumn{3}{|l|}{ Intervalos de Escores Parciais de Sustentabilidade (EPS) } \\
\cline { 2 - 4 } & $\begin{array}{l}\text { Escore Mínimo da } \\
\text { Dimensão }\end{array}$ & $\begin{array}{l}\text { Escore Médio da } \\
\text { Dimensão }\end{array}$ & Escore Máximo Dimensão \\
\hline Ambiental & 35,643 & 71,286 & 106,929 \\
\hline Econômica & 29,179 & 58,358 & $\mathbf{8 7 , 5 3 7}$ \\
\hline Social & $\mathbf{2 8 , 4 8 3}$ & $\mathbf{5 9 , 6 6 6}$ & $\mathbf{8 5 , 4 4 9}$ \\
\hline
\end{tabular}

Fonte: Callado (2010).

Para cada dimensão de sustentabilidade avaliada, o Escore Parcial de Sustentabilidade (EPS) calculado assumirá um valor que representará o resultado obtido por uma empresa em uma determinada dimensão, a saber: zero, quando a empresa estudada obtiver um valor de desempenho inferior ao Escore médio; e valor um, caso a empresa avaliada apresente um valor de desempenho igual ou superior ao Escore médio, de acordo com a Tabela 03. 
Tabela 03: Intervalos de Escores Parciais de Sustentabilidade (EPS)

\begin{tabular}{|l|l|l|l|l|}
\hline \multirow{2}{*}{ DIMENSÃO } & \multicolumn{3}{|l|}{ Intervalos de Escores Parciais de Sustentabilidade (EPS) } \\
\cline { 2 - 5 } & $\begin{array}{l}\text { Resultado das } \\
\text { Dimensões }\end{array}$ & $\begin{array}{l}\text { Valor atribuído ao } \\
\text { desempenho do } \\
\text { hotel }\end{array}$ & $\begin{array}{l}\text { Resultado das } \\
\text { dimensões }\end{array}$ & $\begin{array}{l}\text { Valor atribuído ao } \\
\text { desempenho do hotel }\end{array}$ \\
\hline Ambiental & EPSa $<71,286$ & 0 (zero) & EPSa $\leq 71,286$ & 1 (um) \\
\hline Econômica & EPSe $<58,538$ & 0 (zero) & EPSe $\leq 58,538$ & 1 (um) \\
\hline Social & EPSs $<56,966$ & 0 (zero) & EPSs $\leq 56,966$ & 1 (um) \\
\hline
\end{tabular}

Fonte: Callado (2010).

Para cada dimensão de sustentabilidade investigada, o Escore Parcial de Sustentabilidade (EPS) calculado assumirá um valor que representa o resultado obtido para cada dimensão, sendo zero, quando o valor de desempenho for inferior ao Escore médio da dimensão analisada; e um, quando a empresa analisada apresentar um valor de desempenho igual ou superior ao Escore médio da dimensão analisada. Na Tabela 04, pode-se observar os valores assumidos por cada Escore Parcial de Sustentabilidade (EPS) e os resultados utilizados para sua definição.

Tabela 04: Resultados e interpretações dos EPS relativo às três dimensões

\begin{tabular}{|l|l|l|}
\hline Resultado da Empresa & Interpretação & $\begin{array}{l}\text { Valor atribuído ao Escore Parcial } \\
\text { de Sustentabilidade (EPS) }\end{array}$ \\
\hline $\begin{array}{l}\text { Escore menor que o Escore médio da } \\
\text { dimensão }\end{array}$ & $\begin{array}{l}\text { Desempenho } \\
\text { insatisfatório }\end{array}$ & 0 (zero) \\
\hline $\begin{array}{l}\text { Escore maior ou igual ao Escore médio da } \\
\text { dimensão }\end{array}$ & Desempenho satisfatório & 1 (um) \\
\hline
\end{tabular}

Fonte: Callado (2010).

\section{INTEGRAÇÃO DE ESCORES PARCIAIS DE SUSTENTABILIDADE POR MEIO DA LOCALIZAÇÃO DE EMPRESAS NO GSE}

$\mathrm{Na}$ terceira e última etapa do modelo, é realizada a integralização dos EPS e considerado que, quando analisadas as três dimensões de sustentabilidade conjuntamente, elas assumem uma representação tridimensional, que integra seus diferentes aspectos, proposta como GSE e composta por oito posicionamentos espaciais. "A partir da tridimensionalidade destes componentes analisados, é possível localizar espacialmente uma ou mais empresas por meio de resultados de indicadores de desempenho das dimensões consideradas" (CALLADO, 2010, p. 90). 
As composições de resultados que definem os diferentes posicionamentos espaciais do Grid de Sustentabilidade Empresarial (GSE) podem ser observadas na Tabela 05.

Tabela 05: Composições de resultados e posicionamentos espaciais do GSE

\begin{tabular}{|c|c|c|c|c|}
\hline \multicolumn{4}{|l|}{ RESULTADOS } & \multirow{2}{*}{$\begin{array}{l}\text { Posicionamento } \\
\text { no Grid de } \\
\text { Sustentabilidade } \\
\text { Empresarial (GSE) }\end{array}$} \\
\hline $\begin{array}{l}\text { Escore Parcial de } \\
\text { Sustentabilidade } \\
\text { Econômica (EPSe) }\end{array}$ & $\begin{array}{l}\text { Escore Parcial de } \\
\text { Sustentabilidade } \\
\text { Social (EPSs) }\end{array}$ & $\begin{array}{l}\text { Escore Parcial de } \\
\text { Sustentabilidade } \\
\text { Ambiental (EPSa) }\end{array}$ & $\begin{array}{l}\text { Escore Parcial de } \\
\text { Sustentabilidade } \\
\text { Empresarial (ESE) }\end{array}$ & \\
\hline 0 & 0 & 0 & 0 & I \\
\hline 0 & 0 & 1 & 1 & II \\
\hline 0 & 1 & 0 & 1 & III \\
\hline 1 & 0 & 0 & 1 & IV \\
\hline 1 & 1 & 0 & 2 & V \\
\hline 0 & 1 & 1 & 2 & VI \\
\hline 1 & 0 & 1 & 2 & VII \\
\hline 1 & 1 & 1 & 3 & VIII \\
\hline
\end{tabular}

Fonte: Callado (2010).

\section{RESULTADOS}

\section{ESCORES PARCIAIS DE SUSTENTABILIDADE (EPS)}

Os resultados dos Escores Parciais de Sustentabilidade das três dimensões observadas no Grid de Sustentabilidade Empresarial (GSE) estão baseados no modelo triple bottom line, ou seja, a dimensão ambiental, econômica e social.

A sustentabilidade foi mensurada por meio dos indicadores do GSE e, para cada dimensão analisada, os resultados são apresentados utilizando o mesmo critério usado pelo autor do modelo GSE.

\section{ESCORE PARCIAL DE SUSTENTABILIDADE DA DIMENSÃO AMBIENTAL (EPSA)}

A dimensão ambiental leva em consideração os desempenhos dos hotéis referentes aos 16 indicadores ambientais de sustentabilidade, conforme mostra a Tabela 6. 
Tabela 6: Escores de desempenho dos hotéis em indicadores ambientais

\begin{tabular}{|c|c|c|c|c|c|c|c|c|c|c|c|c|c|c|c|c|c|c|c|c|c|c|}
\hline \multirow{2}{*}{$\begin{array}{l}\text { DIMENSÅO } \\
\text { INDICADORES } \\
\end{array}$} & \multicolumn{22}{|c|}{ HOTÉIS } \\
\hline & & 2 & 3 & 45 & 6 & 78 & 9 & 10 & 11 & 12 & 13 & 14 & 15 & 16 & 17 & 18 & 19 & 20 & 21 & 22 & 23 & \\
\hline $\begin{array}{l}\text { Sistema de Gestão } \\
\text { Ambiental }\end{array}$ & 3 & 1 & & $\begin{array}{ll}3 & 1\end{array}$ & 3 & 13 & 1 & 3 & 2 & 2 & 1 & 2 & 1 & 3 & 1 & 1 & 1 & 1 & 3 & 1 & 3 & \\
\hline $\begin{array}{l}\text { Quantidade de } \\
\text { água utilizada }\end{array}$ & 2 & 2 & 2 & 12 & 1 & 11 & 1 & 2 & 2 & 2 & 1 & 1 & 3 & 2 & 2 & 1 & 1 & 1 & 1 & 2 & 1 & \\
\hline $\begin{array}{l}\text { Processos } \\
\text { decorrentes de } \\
\text { infrações } \\
\text { ambientais }\end{array}$ & 1 & 3 & 3 & 33 & 1 & 32 & 3 & 3 & 3 & 3 & 3 & 3 & 3 & 3 & 3 & 3 & 3 & 3 & 3 & 3 & 3 & \\
\hline $\begin{array}{l}\text { Treinamento, } \\
\text { educação e } \\
\text { capacitação em } \\
\text { aspectos } \\
\text { ambientais }\end{array}$ & 2 & 1 & 13 & 32 & 2 & 23 & 2 & 3 & 3 & 3 & 1 & 2 & 3 & 2 & 1 & 1 & 1 & 1 & 3 & 2 & 3 & \\
\hline $\begin{array}{l}\text { Economia de } \\
\text { energia }\end{array}$ & 2 & 1 & 2 & 13 & 2 & 11 & 1 & 2 & 3 & 3 & 1 & 1 & 3 & 2 & 1 & 2 & 1 & 1 & 1 & 2 & 1 & \\
\hline $\begin{array}{c}\text { Desenvolvimento } \\
\text { de tecnologias } \\
\text { equilibradas }\end{array}$ & 2 & 1 & 12 & 22 & 2 & 11 & 2 & 2 & 2 & 2 & 1 & 1 & 2 & 1 & 1 & 1 & 2 & 2 & 1 & 1 & 2 & \\
\hline $\begin{array}{l}\text { Ciclo de vida de } \\
\text { produtos e } \\
\text { serviços }\end{array}$ & 1 & 1 & 1 & 11 & 1 & 11 & 1 & 1 & 1 & 1 & 1 & 1 & 1 & 1 & 1 & 1 & 1 & 1 & 1 & 1 & 3 & \\
\hline $\begin{array}{l}\text { Quantidade de } \\
\text { combustível fóssil } \\
\text { utilizado por ano }\end{array}$ & 3 & 3 & 2 & 12 & 2 & 22 & 2 & 2 & 2 & 2 & 1 & 2 & 3 & 3 & 1 & 2 & 1 & 1 & 3 & 2 & 3 & \\
\hline $\begin{array}{c}\text { Reciclagem e } \\
\text { utilização de água }\end{array}$ & 1 & 1 & 2 & 11 & 2 & 11 & 1 & 1 & 1 & 1 & 1 & 1 & 1 & 3 & 1 & 1 & 1 & 1 & 3 & 1 & 3 & \\
\hline $\begin{array}{l}\text { Acidentes } \\
\text { ambientais }\end{array}$ & 3 & 3 & 33 & 33 & 3 & 33 & 3 & 3 & 3 & 3 & 3 & 3 & 3 & 3 & 3 & 3 & 3 & 3 & 3 & 3 & 3 & \\
\hline $\begin{array}{c}\text { Fontes de recursos } \\
\text { utilizados }\end{array}$ & 1 & 1 & 2 & 22 & 2 & 11 & 2 & 1 & 3 & 3 & 3 & 2 & 3 & 2 & 1 & 1 & 2 & 2 & 2 & 2 & 1 & \\
\hline $\begin{array}{l}\text { Redução de } \\
\text { resíduos }\end{array}$ & 3 & 3 & 2 & 22 & 2 & 22 & 2 & 2 & 2 & 2 & 1 & 3 & 2 & 2 & 2 & 2 & 1 & 1 & 2 & 1 & 3 & \\
\hline $\begin{array}{l}\text { Produção de } \\
\text { resíduos tóxicos }\end{array}$ & 3 & 3 & 33 & 33 & 3 & 33 & 2 & 2 & 3 & 3 & 3 & 3 & 2 & 3 & 3 & 3 & 2 & 2 & 2 & 3 & 3 & \\
\hline ISO 14001 & 1 & 1 & 1 & 11 & 1 & 11 & 1 & 1 & 1 & 1 & 1 & 1 & 1 & 1 & 1 & 1 & 1 & 1 & 1 & 1 & 1 & \\
\hline Qualidade do solo & 3 & 3 & 3 & 33 & 3 & 33 & 3 & 3 & 3 & 3 & 3 & 3 & 3 & 3 & 3 & 3 & 3 & 3 & 3 & 3 & 3 & \\
\hline $\begin{array}{l}\text { Qualidade de água } \\
\text { de superfície }\end{array}$ & 3 & 3 & 3 & 33 & 3 & 33 & 3 & 3 & 3 & 3 & 3 & 3 & 3 & 3 & 3 & 3 & 3 & 3 & 3 & 3 & 3 & \\
\hline
\end{tabular}

Fonte: Dados da pesquisa, 2017.

Observa-se que os hotéis investigados obtiveram resultados idênticos em quatro dos 16 indicadores considerados, sendo eles: acidentes ambientais, ISO 14001, qualidade do solo e qualidade de águas de superfície. Para os indicadores associados aos acidentes ambientais, qualidade do solo e qualidade de águas de superfície, as empresas analisadas obtiveram o escore máximo. $\mathrm{O}$ indicador "acidentes ambientais" revela que nenhum dos 
hotéis investigados teve registros de acidentes ambientais no último ano; isso indica que as empresas mostram atenção nesse quesito, além deste indicador estar atrelado, principalmente, às ações que a lei determina.

Os outros dois indicadores "qualidade do solo" e "qualidade de águas de superfície", que também obtiveram o escore máximo, indicam que as atividades desenvolvidas pela empresa não geram danos ao solo nem às águas de superfície. Isso revela o cuidado das empresas com o solo e com a água e sua preocupação em não causar danos ambientais. Essas constatações coadunam com o trabalho de Malta, Mariani e Oliveira Arruda (2015).

Após ter apresentado o desempenho dos hotéis investigados de forma abrangente, foram calculadas as pontuações totais referentes à dimensão ambiental obtidas por esses hotéis. Os resultados dos Escores Parciais de Sustentabilidade da Dimensão Ambiental dos 23 hotéis analisados foram totalizados a partir da soma dos desempenhos obtidos nos 16 indicadores ambientais, apurando o desempenho geral obtido, disposto na Tabela 7.

Tabela 7 - Escores Parciais de Sustentabilidade da Dimensão Ambiental

\begin{tabular}{|c|c|c|c|}
\hline Hotel & Pontuação Obtida & EPSa & Desempenho \\
\hline 1 & 72,001 & 1 & Satisfatório \\
\hline 2 & 73,715 & 1 & Satisfatório \\
\hline 3 & 76,465 & 1 & Satisfatório \\
\hline 4 & 70,501 & 0 & Insatisfatório \\
\hline 5 & 81,251 & 1 & Satisfatório \\
\hline 6 & 70,001 & 0 & Insatisfatório \\
\hline 7 & 69,965 & 0 & Insatisfatório \\
\hline 8 & 65,965 & 0 & Insatisfatório \\
\hline 9 & 72,108 & 1 & Satisfatório \\
\hline 10 & 73,108 & 1 & Satisfatório \\
\hline 11 & 83,751 & 1 & Satisfatório \\
\hline 12 & 83,751 & 1 & Satisfatório \\
\hline 13 & 67,215 & 0 & Insatisfatório \\
\hline 14 & 71,715 & 1 & Satisfatório \\
\hline 15 & 88,358 & 1 & Satisfatório \\
\hline 16 & 79,215 & 1 & Satisfatório \\
\hline 17 & 67,715 & 0 & Insatisfatório \\
\hline 18 & 69,465 & 0 & Insatisfatório \\
\hline 19 & 65,358 & 0 & Insatisfatório \\
\hline 20 & 65,358 & 0 & Insatisfatório \\
\hline 21 & 75,072 & 1 & Satisfatório \\
\hline 22 & 74,715 & 1 & Satisfatório \\
\hline 23 & 87,715 & Satisfatório \\
\hline
\end{tabular}

Fonte: Dados da pesquisa, 2017. 
De acordo com estes resultados, observa-se que, dos 23 hotéis investigados, $61 \%$ dos hotéis apresentam desempenhos satisfatórios, enquanto quWe 39\% dos hotéis, em um número de 09 hotéis, obtiveram resultados insatisfatórios. Este panorama diverge com os estudos de Andrade (2012), que investigou 27 hotéis e apurou um resultado em que somente 7\% dos hotéis apresentaram desempenhos insatisfatórios nos Escores Parciais de Sustentabilidade da Dimensão Ambiental, e 93\% obtiveram escores iguais ou superiores ao Escore Médio, apresentando desempenho satisfatório. Prosseguindo com o cálculo do Escore Parcial de Sustentabilidade, na seção seguinte são apresentados os resultados obtidos referentes à dimensão econômica, por meio do Escore Parcial de Sustentabilidade da dimensão econômica (EPSe).

\section{ESCORE PARCIAL DE SUSTENTABILIDADE DA DIMENSÃO ECONÔMICA (EPSE)}

O segundo aspecto da sustentabilidade considerado foi o desempenho das empresas investigadas em relação aos 14 indicadores de desempenho referentes à dimensão econômica. Os resultados dos 23 hotéis estão sumarizados na Tabela 8.

Tabela 8: Escores de desempenho dos hotéis em indicadores econômicos

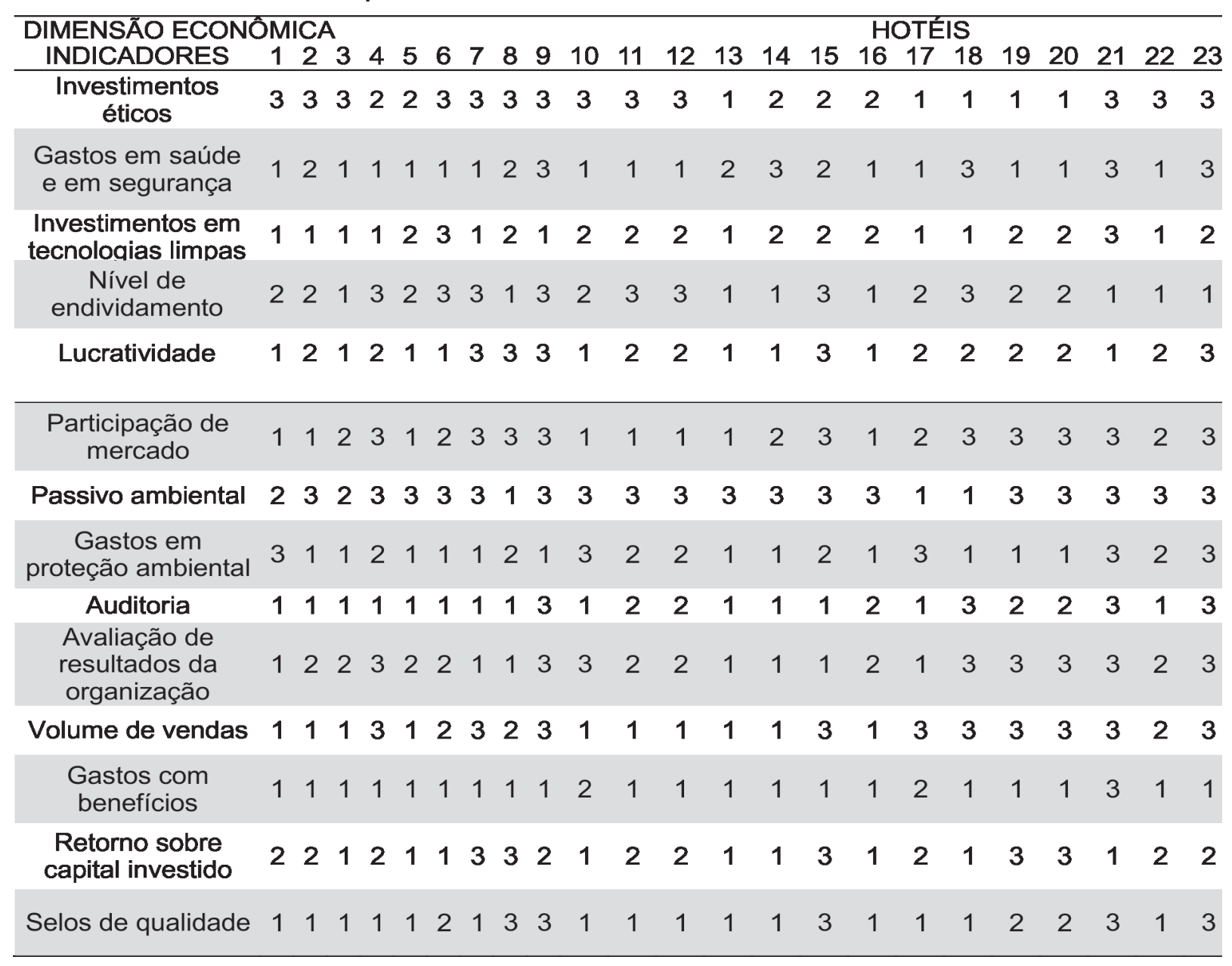

Fonte: Dados da pesquisa, 2017. 
Pode-se observar que todos os 23 hotéis investigados obtiveram resultados distintos para os indicadores de sustentabilidade da dimensão econômica, diferentemente dos indicadores da dimensão ambiental, em que ocorreram resultados idênticos em quatro indicadores daquela dimensão. Alguns indicadores de sustentabilidade podem ser destacados: os indicadores "investimentos éticos", "participação de mercado" e "passivo ambiental", por apresentarem predominantemente resultados com escores superiores.

O indicador de desempenho referente à dimensão econômica "gastos com benefícios" é o que evidenciou menor resultado. O parâmetro deste indicador é analisar os gastos com pensões e demais benefícios. Dessa forma, aproximadamente 90\% dos hotéis investigados não possuem ou oferecem planos de pensões e aposentadorias e demais benefícios a nenhum de seus funcionários. Somente 01 hotel assinalou possuir ou oferecer planos de pensões e aposentadorias e demais benefícios a todos os funcionários.

Após apresentar o desempenho dos hotéis, foi realizado o cálculo da pontuação total de desempenho, a partir do somatório do desempenho dos 14 indicadores econômicos, e classificados os desempenhos apresentados em relação ao intervalo de valores do Escore Parcial desta dimensão. Os resultados estão dispostos na Tabela 9.

Tabela 9: Escores Parciais de Sustentabilidade da Dimensão Econômica

\begin{tabular}{|c|c|c|c|}
\hline Hotel & Pontuação Obtida & EPSe & Desempenho \\
\hline 1 & 52,500 & 0 & Insatisfatório \\
\hline 2 & 48,608 & 0 & Insatisfatório \\
\hline 3 & 40,465 & 0 & Insatisfatório \\
\hline 4 & 58,394 & 0 & Insatisfatório \\
\hline 5 & 42,072 & 0 & Insatisfatório \\
\hline 6 & 54,679 & 0 & Insatisfatório \\
\hline 7 & 58,465 & 1 & Insatisfatório \\
\hline 8 & 59,144 & 1 & Satisfatório \\
\hline 9 & 72,608 & 0 & Satisfatório \\
\hline 10 & 53,144 & 0 & Insatisfatório \\
\hline 11 & 54,715 & 0 & Insatisfatório \\
\hline 12 & 54,715 & 0 & Insatisfatório \\
\hline 13 & 35,179 & 0 & Insatisfatório \\
\hline 14 & 43,929 & 1 & Insatisfatório \\
\hline 15 & 66,358 & 0 & Satisfatório \\
\hline 16 & 42,072 & 0 & Insatisfatório \\
\hline 17 & 47,608 & 0 & Insatisfatório \\
\hline 18 & 55,322 & 1 & Insatisfatório \\
\hline 19 & 60,144 & 1 & Satisfatório \\
\hline 20 & 60,144 & 1 & Satisfatório \\
\hline 21 & 75,251 & 0 & Satisfatório \\
\hline 22 & 50,894 & Insatisfatório \\
\hline 23 & 75,430 & 0 satisfatório \\
\hline
\end{tabular}

Fonte: Dados da pesquisa, 2017. 
Pode-se observar que somente 07 hotéis, ou seja, 30\% dos 23 hotéis investigados, apresentam desempenhos satisfatórios nos Escores Parciais de Sustentabilidade da Dimensão Econômica. Os demais 70\% dos hotéis apresentam desempenho abaixo do Escore Médio desta dimensão. O estudo de Andrade (2012) apresentou um cenário diferente, em que se observou que somente 05 dos 27 hotéis investigados apresentam desempenhos insatisfatórios nos Escores Parciais de Sustentabilidade da Dimensão Econômica, enquanto que o restante dos hotéis obteve Escores iguais ou superiores ao Escore Médio, apresentando desempenho satisfatório.

\section{ESCORE PARCIAL DE SUSTENTABILIDADE DA DIMENSÃO SOCIAL (EPSS)}

Na Tabela 10, é tratada a terceira dimensão da sustentabilidade, a Social, analisandose os 13 indicadores de desempenho da dimensão estudada, os quais são considerados no modelo GSE.

Tabela 10 - Escores de desempenho dos hotéis em indicadores sociais

\begin{tabular}{|c|c|c|c|c|c|c|c|c|c|c|c|c|c|c|c|c|c|c|c|c|c|c|c|}
\hline \multirow{2}{*}{$\begin{array}{l}\text { DIMENSÃO } \\
\text { INDICADORES }\end{array}$} & \multicolumn{23}{|c|}{ HOTÉIS } \\
\hline & 1 & 2 & 34 & 45 & 6 & 7 & 8 & 9 & 10 & 11 & 12 & 13 & 14 & 15 & 16 & 1 & & 18 & 19 & 20 & 21 & 22 & 23 \\
\hline $\begin{array}{l}\text { Gera } \\
\text { trabalh }\end{array}$ & 3 & 3 & 33 & 33 & 3 & 3 & 1 & 3 & 3 & 3 & 3 & 3 & 3 & 3 & 3 & 3 & & 3 & 3 & 3 & 3 & 3 & 3 \\
\hline $\begin{array}{l}\text { Auxílio em } \\
\text { educação e } \\
\text { treinamento }\end{array}$ & 2 & 1 & & 12 & 2 & 2 & 2 & 2 & 1 & 2 & 2 & 1 & 2 & 3 & 1 & 2 & & 1 & 2 & 2 & 3 & 1 & 3 \\
\hline $\begin{array}{l}\text { Padrão de } \\
\text { segurança de } \\
\text { trabalho }\end{array}$ & 3 & 2 & & 12 & 3 & 1 & 3 & 3 & 2 & 3 & 3 & 3 & 1 & 3 & 3 & & & 3 & 3 & 3 & 3 & 2 & 2 \\
\hline $\begin{array}{c}\text { Ética } \\
\text { organizacional }\end{array}$ & 2 & 2 & 21 & 11 & & 2 & 2 & 3 & 2 & 2 & 2 & 1 & 2 & 1 & 1 & & & 1 & 2 & 2 & 3 & 2 & 3 \\
\hline Interação social & 1 & 1 & 11 & 11 & 2 & 1 & 1 & 2 & 1 & 2 & 2 & 1 & 1 & 2 & 1 & & & 2 & $r$ & r & 0 & 2 & 0 \\
\hline $\begin{array}{l}\text { Empregabilidade e } \\
\text { gerenciamento de } \\
\text { fim de carreira }\end{array}$ & 1 & 1 & 11 & 11 & 1 & 1 & 1 & 1 & 1 & 1 & 1 & 1 & 1 & 1 & 1 & & & 2 & 1 & 1 & 3 & 2 & 2 \\
\hline $\begin{array}{c}\text { Políticas de } \\
\text { distribuição de } \\
\text { lucros e resultados }\end{array}$ & 1 & 1 & 11 & 11 & 2 & 1 & 1 & 1 & 1 & 1 & 1 & 1 & 1 & 1 & 1 & & & 1 & 1 & 1 & 3 & 1 & 1 \\
\hline $\begin{array}{l}\text { Conduta de padrão } \\
\text { internacional }\end{array}$ & 1 & 1 & 22 & 21 & & 1 & 2 & 2 & 3 & 2 & 2 & 1 & 2 & 1 & 1 & 1 & & 1 & 1 & 1 & 2 & 2 & 3 \\
\hline $\begin{array}{c}\text { Capacitação e } \\
\text { desenvolvimento }\end{array}$ & 3 & 1 & 11 & 11 & 3 & 2 & 2 & 3 & 3 & 2 & 2 & 2 & 3 & 1 & 1 & & & 2 & 1 & 1 & 3 & 2 & 3 \\
\hline Acidentes fatais & 3 & 3 & 33 & 33 & 3 & 3 & 3 & 3 & 3 & 3 & 3 & 3 & 3 & 3 & 3 & & & 3 & 3 & 3 & 3 & 3 & 3 \\
\hline n & 3 & 1 & 33 & 33 & 3 & 3 & 3 & 3 & 3 & 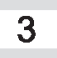 & 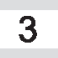 & 3 & 3 & 3 & $?$ & & & 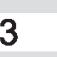 & 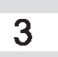 & 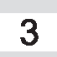 & 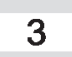 & 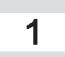 & 3 \\
\hline Stress de trabalho & 1 & 2 & 11 & 11 & 1 & 1 & 1 & 1 & 1 & 2 & 2 & 1 & 1 & 1 & 1 & & & 1 & 1 & 1 & 3 & 1 & 1 \\
\hline $\begin{array}{r}\text { Segur } \\
\text { pro }\end{array}$ & 1 & 3 & 11 & 12 & 3 & & 2 & 2 & 2 & 2 & 2 & 1 & 2 & 1 & I & 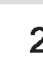 & & 1 & 2 & 2 & 1 & 1 & 3 \\
\hline
\end{tabular}

Nota. Fonte: Dados da pesquisa, 2017. 
De acordo com os resultados, observa-se que todos os hotéis investigados obtiveram resultados idênticos em um indicador de sustentabilidade social, "acidentes fatais", o qual analisa a ocorrência de acidentes fatais associados ao trabalho. Todas as empresas obtiveram escore máximo de desempenho, afirmando que não houve acidentes fatais associados ao trabalho no último ano. Outro indicador de sustentabilidade social que se destacou é o indicador "contratos legais", o qual busca analisar as características dos contratos que regem a relação entre proprietários e funcionários da empresa. Assim, esse indicador apresentou um escore máximo para 21 hotéis, que informaram que possuem contratos de trabalho e todos se encontram em situação regular. Dessa forma, é demonstrado que os hotéis mantêm seu quadro de funcionários em situação regular, conforme determinado pela legislação trabalhista.

Após apresentado o desempenho dos hotéis, foi realizado o cálculo da pontuação total de desempenho, a partir do somatório do desempenho dos 13 indicadores sociais e classificado o desempenho em relação ao intervalo de valores do Escore Parcial desta dimensão, conforme mostra a Tabela 11.

Tabela 11: Escores Parciais de Sustentabilidade da Dimensão Social

\begin{tabular}{|c|c|c|c|}
\hline Hotel & Pontuação Obtida & EPSs & Desempenho \\
\hline 1 & 56,788 & 0 & Insatisfatório \\
\hline 2 & 48,965 & 0 & Insatisfatório \\
\hline 3 & 49,144 & 0 & Insatisfatório \\
\hline 4 & 44,769 & 0 & Insatisfatório \\
\hline 5 & 49,162 & 0 & Insatisfatório \\
\hline 6 & 68,609 & 1 & Satisfatório \\
\hline 7 & 49,859 & 0 & Insatisfatório \\
\hline 8 & 53,072 & 0 & Insatisfatório \\
\hline 9 & 64,984 & 1 & Satisfatório \\
\hline 10 & 57,823 & 1 & Satisfatório \\
\hline 11 & 62,323 & 1 & Satisfatório \\
\hline 12 & 62,323 & 1 & Satisfatório \\
\hline 13 & 49,984 & 0 & Insatisfatório \\
\hline 14 & 55,859 & 0 & Insatisfatório \\
\hline 15 & 53,805 & 0 & Insatisfatório \\
\hline 16 & 47,555 & 0 & Insatisfatório \\
\hline 17 & 68,806 & 1 & Satisfatório \\
\hline 18 & 53,984 & 0 & Insatisfatório \\
\hline 19 & 53,787 & 0 & Insatisfatório \\
\hline 20 & 53,787 & 0 & Insatisfatório \\
\hline 21 & 80,021 & 1 & Satisfatório \\
\hline 22 & 51,251 & 0 & Insatisfatório \\
\hline 23 & 72,305 & 1 & Satisfatório \\
\hline
\end{tabular}

Nota. Fonte: Dados da pesquisa, 2017. 
Pode-se observar o desempenho dos hotéis para a dimensão social, em que 08 hotéis, ou seja, 35\% dos 23 hotéis investigados apresentam desempenhos satisfatórios nos Escores Parciais de Sustentabilidade da Dimensão Social. Os demais 15 hotéis apresentam desempenho abaixo do Escore Médio desta dimensão. Os resultados desta dimensão destoam com o estudo de Andrade (2012), em que se observou que cinco dos 27 hotéis investigados apresentam desempenhos insatisfatórios nos EPSs, enquanto que o restante dos hotéis obteve escores iguais ou superiores ao Escore Médio, apresentando desempenho satisfatório.

Após a apresentação das interações entre os Escores Parciais de Sustentabilidade (EPS) das dimensões das empresas, aliada com a representação dos Escores de Sustentabilidade Empresarial (ESE) nas quatro faixas de sustentabilidade, é realizada a classificação dos 23 hotéis estudados, a qual pode ser visualizada na Tabela 12, conforme os 8 posicionamentos espaciais que formam o Grid de Sustentabilidade Empresarial (GSE).

Tabela 12: Posicionamentos espaciais do GSE

\begin{tabular}{|c|r|r|r|l|}
\hline \multicolumn{1}{|l|}{ RESULTADOS } & \multicolumn{1}{|c|}{$\begin{array}{l}\text { Posição no } \\
\text { Empresarial }\end{array}$} \\
\hline 0 & 0 & 0 & 0 & Prid de Sustentabilidade \\
\hline 0 & 0 & 1 & 1 & Posição I \\
\hline 0 & 1 & 0 & 1 & Posição II \\
\hline 1 & 0 & 0 & 1 & Posição III \\
\hline 1 & 1 & 0 & 2 & Posição IV \\
\hline 0 & 1 & 1 & 2 & Posição V \\
\hline 1 & 0 & 1 & 2 & Posição VI \\
\hline 1 & 1 & 1 & 3 & Posição VII \\
\hline
\end{tabular}

Fonte: Callado (2010). 
Rev.Tur., Visão e Ação, v21, n2, p102-127, Mai./Ago. 2019 - Balneário Camboriú, Santa Catarina, Brasil

Seguindo o modelo GSE, apresentam-se, na Tabela 13, as interações que definiram os posicionamentos dos 23 hotéis de Foz do Iguaçu, PR.

Tabela 13: Resultados dos Escores Sustentabilidade Empresarial (ESE) segundo o (GSE)

\begin{tabular}{|c|c|c|c|c|c|}
\hline \multirow[b]{2}{*}{ Hotéis } & \multicolumn{5}{|c|}{ Resultados } \\
\hline & EPSa & EPSe & EPSs & ESSE & $\begin{array}{l}\text { Posicionamento no Grid de Sustentabilidade } \\
\text { Empresarial }\end{array}$ \\
\hline 1 & 1 & 0 & 0 & 1 & II \\
\hline 2 & 1 & 0 & 0 & 1 & II \\
\hline 3 & 1 & 0 & 0 & 1 & II \\
\hline 4 & 0 & 0 & 0 & 0 & 1 \\
\hline 5 & 1 & 0 & 0 & 1 & II \\
\hline 6 & 0 & 0 & 1 & 1 & III \\
\hline 7 & 0 & 0 & 0 & 0 & 1 \\
\hline 8 & 0 & 1 & 0 & 1 & IV \\
\hline 9 & 1 & 1 & 1 & 3 & VIII \\
\hline 10 & 1 & 0 & 1 & 2 & $\mathrm{VI}$ \\
\hline 11 & 1 & 0 & 1 & 2 & VI \\
\hline 12 & 1 & 0 & 1 & 2 & VI \\
\hline 13 & 0 & 0 & 0 & 0 & 1 \\
\hline 14 & 1 & 0 & 0 & 1 & II \\
\hline 15 & 1 & 1 & 0 & 2 & VII \\
\hline 16 & 1 & 0 & 0 & 1 & II \\
\hline 17 & 0 & 0 & 1 & 1 & III \\
\hline 18 & 0 & 0 & 0 & 0 & 1 \\
\hline 19 & 0 & 1 & 0 & 1 & IV \\
\hline 20 & 0 & 1 & 0 & 1 & IV \\
\hline 21 & 1 & 1 & 1 & 3 & VIII \\
\hline 22 & 1 & 0 & 0 & 1 & II \\
\hline 23 & 1 & 1 & 1 & 3 & VIII \\
\hline
\end{tabular}

Fonte: Dados da pesquisa, 2017. 
Os posicionamentos dos 23 hotéis no Grid de Sustentabilidade Empresarial (GSE) são apresentados na Figura 2.

Figura 2: Posicionamento dos hotéis de Foz do Iguaçu-PR no GSE.
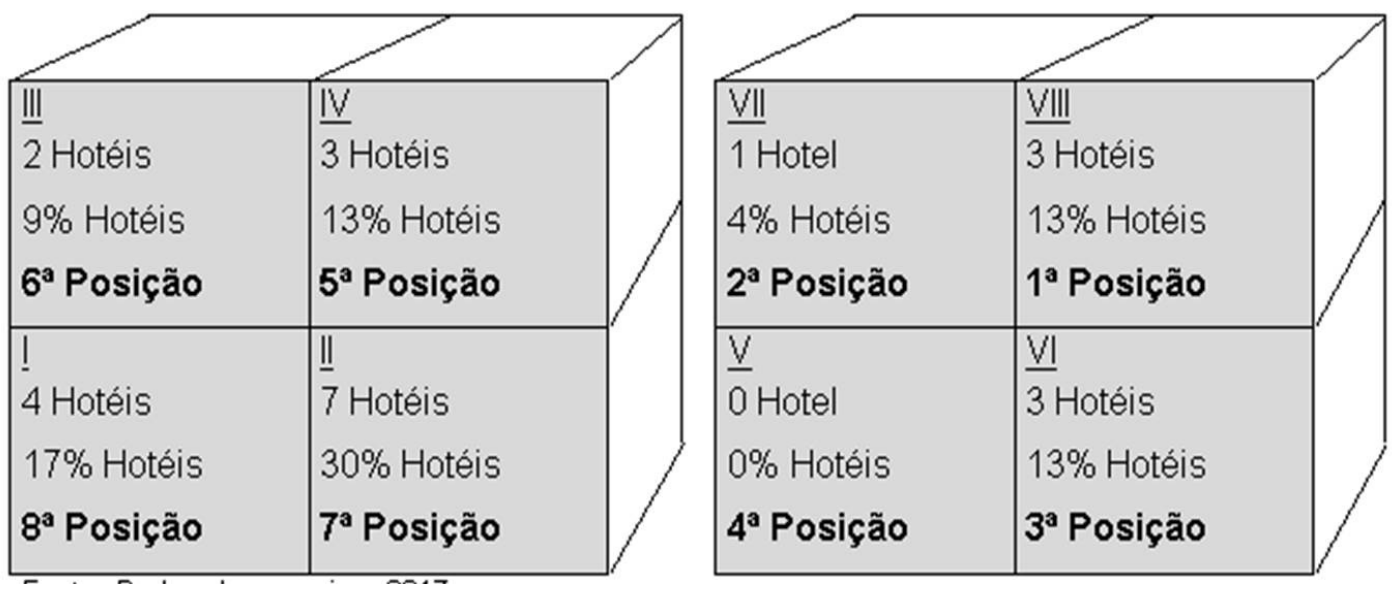

Fonte: Dados da pesquisa, 2017.

a) O posicionamento dos 23 hotéis analisados dentro do GSE obteve a seguinte configuração:

b) Quatro hotéis encontram-se localizados no Quadrante I, ou seja, estes hotéis apresentaram baixo desempenho econômico, não possuem boa interação social, nem são comprometidos com aspectos ambientais;

c) Sete hotéis situam-se no Quadrante II, isto é, obtiveram baixo desempenho econômico, não possuem boa interação social, mas estão comprometidos com aspectos ambientais;

d) Dois hotéis estão relacionados no Quadrante III, caracterizando que esses hotéis obtiveram baixo desempenho econômico, possuem boa interação social, mas não estão comprometidos com aspectos ambientais;

e) Três hotéis foram categorizados no Quadrante IV, expressando que obtiveram bom desempenho econômico, não possuem boa interação social e não estão comprometidos com aspectos ambientais;

f) Nenhum hotel foi identificado no Quadrante $V_{\text {; }}$ dessa forma, não houve hotel com bom desempenho econômico, com boa interação social, mas não está comprometido com aspectos ambientais;

g) Três hotéis estão classificados no Quadrante VI, os quais obtiveram baixo desempenho econômico, mas possuem boa interação social e estão comprometidos com aspectos ambientais;

h) Um hotel aparece no Quadrante VII, o que significa que este hotel obteve bom desempenho econômico, não possui boa interação social e está comprometido com aspectos ambientais; 
A estruturação que é proposta para o Grid de Sustentabilidade conseguiu atingir seu resultado por meio da ilustração do desempenho da sustentabilidade empresarial, dos hotéis de Foz do Iguaçu - PR, calculado a partir do modelo proposto, considerando a integração das dimensões ambiental, econômica e social.

É imprescindível ressaltar que a visualização gráfica do posicionamento fornece uma perspectiva tridimensional sobre a noção de sustentabilidade, associando o posicionamento dos hotéis analisados às suas qualidades e deficiências, assim como foi percebido pelo autor deste modelo em sua experiência.

A análise do GSE, a partir de uma visão tridimensional, facilita a visualização do gestor em relação ao posicionamento da situação do hotel quanto à sua sustentabilidade e ao entendimento do caminho que cada hotel precisa percorrer para alcançar a sustentabilidade empresarial nas três dimensões.

De acordo com os resultados apresentados no GSE, o modelo revelou que $13 \%$ dos hotéis investigados estão posicionados no Quadrante VIII, o que corresponde aos hotéis que obtiveram desempenho superior em todas as dimensões, ou seja, estes hotéis são totalmente sustentáveis nas três dimensões, ambiental, econômica e social. Contudo, este cenário contrasta com os resultados apurados na pesquisa de Andrade (2012), que identificou que 70,4\% dos hotéis investigados estão posicionados no Quadrante VIII e, por consequência, são considerados, de acordo com o modelo, totalmente sustentáveis nas três dimensões.

Para os hotéis que estão localizados nos Quadrante I, II, III e IV, que apresentaram baixo desempenho econômico, são recomendadas algumas ações para melhorar sua posição no GSE: verificar e reconhecer os custos relacionados ao meio ambiente, demonstrar aos stakeholders o quanto a empresa está empenhada em proteger, conservar ou corrigir possíveis impactos ao meio ambiente (Pfitscher, 2004).

Conforme Barbieri e Cajazeira (2012), deve-se buscar trabalhar fatores, como: estratégia de negócio, planejamento, legalidade, normatizações/certificações, governança corporativa, vantagem competitiva, qualidade e custo, foco no cliente, foco no mercado, foco nos funcionários, controles financeiros, resultado, investimentos, equipe qualificada e motivada.

Para os hotéis que estão localizados nos Quadrantes I, II, IV e VII e que apresentaram baixo desempenho no âmbito social, recomendam-se para buscar uma melhor colocação no GSE, a partir das seguintes ações: criar um sistema capaz de inventariar, classificar, registrar, demonstrar, avaliar e explicar os dados sobre a atividade social da entidade, de modo que sejam tomadas decisões para gerenciamento das ações referentes à responsabilidade social (Kroetz, 2000).

Em nível interno, as informações devem expressar as iniciativas relevantes que contribuem para a qualidade de vida na entidade e na promoção humana de seus empregados, tais como: educação profissional e formal, saúde, segurança no trabalho, alimentação e esporte (Kroetz, 2000).

Para os hotéis que estão localizados nos Quadrante I, III e V, que apresentaram baixo desempenho ambiental, são recomendadas algumas ações, para melhorar sua posição no GSE: identificar se a empresa cumpre ou não com a legislação ambiental vigente; comprovar a evolução da atuação ambiental da empresa por meio do tempo e identificar as tendências 
que se observam; detectar as áreas da empresa que necessitam especial atenção (áreas críticas) e os aspectos ambientais significativos; identificar oportunidades para uma melhor gestão dos aspectos ambientais; identificar oportunidades estratégicas: como a empresa pode obter vantagens competitivas graças a melhoras concretas na gestão ambiental: quais são as melhoras que dão valor à companhia; obter informação específica para fazer frente à solicitação dos partícipes concretos (Tinoco \& Robles, 2006).

\section{IMPLICAÇÕES TEÓRICAS E PRÁTICAS}

Esta pesquisa contribui para o campo de estudo da sustentabilidade hoteleira, com o intuito de propor às empresas compreender o conceito de sustentabilidade e se adequarem a ações socioambientais (Carrillo \& Jorge, 2017); possibilitando ainda que outros pesquisadores façam uso desses resultados para elaboração de novas pesquisas, especialmente os apontamentos que tratam das variáveis ambientais apresentadas, pois pode conferir às empresas hoteleiras uma forma de reduzir os impactos ambientais por meio da gestão da sustentabilidade (Corrêa et al. 2014).

Da mesma forma, este estudo possibilita que outros pesquisadores, pessoas ou organizações façam uso dos resultados para refinar suas práticas de desenvolvimento de pesquisas no contexto da gestão da sustentabilidade hoteleira, principalmente em relação às empresas pertencentes ao turismo, que buscam se adaptar à nova realidade de práticas de sustentabilidade orientadas, no âmbito social e ambientalmente responsável em diferentes níveis, desde a mudança de comportamentos até o uso de Sistemas de Gestão Ambiental (Hsiao et al. 2014; Cumo et al.2015; Pace, 2016).

\section{CONSIDERAÇÕES FINAIS}

Ao se propor uma avaliação da sustentabilidade empresarial, por meio do modelo Grid de Sustentabilidade Empresarial (GSE), não se pretendeu obter a completude do tema, mas sim trazer uma contribuição para o tema sustentabilidade, no âmbito científico e empresarial, fomentando o desenvolvimento sustentável da rede hoteleira de Foz do lguaçu - PR, buscando incentivar e criar formas de participação na tomada de decisão nos processos produtivos.

Pelo exposto, está alcançado o objetivo geral deste estudo, evidenciando que o nível de sustentabilidade das empresas hoteleiras de Foz do Iguaçu - PR é considerado de baixo desempenho, de acordo com o modelo GSE nas três dimensões. Portanto, precisam melhorar seu desempenho em busca da sustentabilidade empresarial.

As limitações deste estudo relacionam-se ao número reduzido das empresas hoteleiras investigadas, e também pela resistência ou dificuldade de comunicação e de agenda para viabilizar a coleta dos dados. O estudo limita-se, ainda, aos gestores dos hotéis de Foz do Iguaçu - PR e, por focar em uma amostra específica, não pode ter seus resultados generalizados. Resultados com maior alcance poderiam ser obtidos com a ampliação da pesquisa para clientes, funcionários e demais stakeholders.

Assim, como recomendações para investigações futuras, sugere-se que sejam trabalhadas as seguintes propostas de pesquisa: reaplicar este estudo em outras redes 
hoteleiras, de outras regiões, tendo em vista a importância da mensuração da sustentabilidade empresarial para os meios de hospedagem; aplicar o modelo Grid de Sustentabilidade Empresarial em conjunto com outro modelo de mensuração, visando à comparação dos seus resultados e realizar este estudo em outras organizações turísticas, como agências de turismo receptivo, restaurantes, centros de eventos e órgãos públicos ligados ao turismo.

\section{REFERÊNCIAS BIBLIOGRÁFICAS}

Almeida, F. (2009). O bom negócio da sustentabilidade. Rio de Janeiro: Nova fronteira.

Andrade, J. M. R. D. (2012). Sustentabilidade empresarial: um estudo exploratório nas empresas hoteleiras da região metropolitana de Natal/RN. (Dissertação de Mestrado). Disponível em: http://repositorio.unb.br/ handle/10482/11470

Araújo, G. C., \& Mendonça, P. S. M. (2009). Análise do processo de implantação das normas de sustentabilidade empresarial: um estudo de caso em uma agroindústria frigorífica de bovinos. Revista de Administração Mackenzie, 10(2).

Associação Brasileira de Normas Técnicas (2014). NBR 15401:2014 - Meios de hospedagem - Sistema de gestão da sustentabilidade - Requisitos. Disponível em: <http://www.abnt.org.br/noticias/3013-meios-dehospedagem-sistema-de-gestao-da-sustentabilidade-requisitos>. Acesso em: 26 fev. 2019.

Azapagic, A. (2003). Systems approach to corporate sustainability: a general framework. Process Safety and Environmental Protection, 81(5), 303-316.

Barbieri, J. C.; Cajazeira, J. E., (2012). Responsabilidade social empresarial e empresa sustentável-da teoria à pratica. São Paulo: Editora Saraiva.

Boaventura, E. M. (2007). Metodologia da pesquisa: monografia, dissertação, tese. São Paulo: Atlas.

Bohdanowicz, P. (2006). Environmental awareness and initiatives in the Swedish and Polish hotel industries survey results. International Journal of Hospitality Management, 25(4), 662-682.

Brundtland, G. H. (1985). World commission on environment and development. Environmental policy and law, 14(1), 26-30.

Butler, R. W., Coccossis, H., \& Mexa, A. (2004). Issues in applying carrying capacity concepts: examples from the United Kingdom. The challenge of tourism carrying capacity assessment: theory and practice, 135-149.

Callado, A.L.C., (2010). Modelo de mensuração de sustentabilidade empresarial: uma aplicação em vinícolas localizadas na Serra Gaúcha. (Tese de Doutorado em Agronegócios). Universidade Federal do Rio Grande do Sul. Porto Alegre.

Carrillo, M., \& Jorge, J. M. (2017). Multidimensional analysis of regional tourism sustainability in Spain. Ecological Economics, 140, 89-98.

Chan, W. W. (2005). Partial analysis of the environmental costs generated by hotels in Hong Kong. International Journal of Hospitality Management, 24(4), 517-531.

Coelho, M. F. (2009) A Dinâmica do Hipercentro de Belo Horizonte e a Hotelaria: em busca da sustentabilidade local. (Pós-Graduação em Elaboração, Gestão e Avaliação de Projetos Sociais). Universidade Federal de Minas Gerais. Belo Horizonte.

Coelho, M. D. F., Gosling, M., \& Gonçalves, C. A. (2013). Sustentabilidade e Responsabilidade Social Corporativa como estratégia para a competitividade na Hotelaria. Turismo \& Sociedade. Curitiba, 6(3), 645-670.

Corrêa, L. B., Corrêa, É. K., Peruchin, B., Ferrão, A. L. L da C, \& Guidoni, L. L. C. (2014). Sustentabilidade no Turismo: estudo da gestão ambiental em empreendimento hoteleiro da Região Sul do Brasil. Revista Rosa dos Ventos Turismo e Hospitalidade, 6(4), 583-602.

Cumo, F., Garcia, D. A., Stefanini, V., \& Tiberi, M. (2015). Technologies and strategies to design sustainable tourist accommodations in areas of high environmental value not connected to theelectricity grid. International 
Journal of sustainable development and Planning, 10(1), 20-28.

De Azevedo Irving, M., Sancho, A., \& Melo, G. D. M. (2006). Revisitando significados em sustentabilidade no planejamento turístico. Caderno Virtual de Turismo, 5(4).

Dias, R., \& Pimenta, M. A. (2005). Gestão de hotelaria e turismo. São Paulo: Person Prentice.

Erdogan, N., \& Baris, E. (2007). Environmental protection programs and conservation practices of hotels in Ankara, Turkey. Tourism Management, 28(2), 604-614.

Gil, A. C. (2008). Métodos e técnicas de pesquisa social. (6. Ed) São Paulo: Atlas.

Hsiao, T. Y., Chuang, C. M., Kuo, N. W., \& Yu, S. M. F. (2014). Establishing attributes of an environmental management system for green hotel evaluation. International Journal of Hospitality Management, 36, $197-$ 208.

Henderson, J. C. (2007). Corporate social responsibility and tourism: Hotel companies in Phuket, Thailand, after the Indian Ocean tsunami. International Journal of Hospitality Management, 26(1), 228-239.

Horng, J. S., Liu, C. H., Chou, S. F., Tsai, C. Y., \& Chung, Y. C. (2017). From innovation to sustainability: Sustainability innovations of eco-friendly hotels in Taiwan. International Journal of Hospitality Management, 63, 44-52.

Irving. D, M. A., Bursztyn, I., Sancho, A.P., \& Melo, G. D. M. (2005). Revisitando significados em sustentabilidade no planejamento turístico. Caderno Virtual de Turismo, 5(4).

Krajnc, D. \& Glavic, P. (2005). A model for integrated assessment of sustainable development. Resources, Conservation and Recycling, 43(2).

Kroetz, C. E. S. (2000). Balanço social: teoria e prática. São Paulo: Atlas.

Le, Y., Hollenhorst, S., Harris, C., McLaughlin, W., \& Shook, S. (2006). Environmental management: a study of Vietnamese hotels. Annals of Tourism Research, 33(2), 545-567.

Lorenzetti, D. H.; Cruz, R. M. \& Ricioli, S., (2008). Estratégia empresarial e sustentabilidade: um modelo integrador. Revista da Pós-graduação: Administração, Osasco, 2(3), 33-57.

Malta, M. C. M., Mariani, M. A. P., \& Oliveira A. D., (2015). Sustentabilidade e Gestão de Empreendimentos Hoteleiros: Analisando Hotéis de Campo Grande, Mato Grosso do Sul. ROSA DOS VENTOS. Turismo e Hospitalidade, $7(3)$.

Mendes, J. M. G. (2009) Dimensões da sustentabilidade. Revista das Faculdades Santa Cruz, 7(2), 49-59.

Molina, J. F.A., Cortés, E.C., Moliner, J.P, \& Tarí, J. J. (2009). Environmental practices and firm performance: an empirical analysis in the Spanish hotel industry. Journal of Cleaner Production, 17(5), 516-524.

Oliveira, N. G. I. (2005) Desenvolvimento Sustentável e Noção de Sustentabilidade. In: N.G.I. Oliveira, C.H.B. Martins (Org.). Indicadores Econômico-Ambientais na Perspectiva da Sustentabilidade. 12-120. Porto Alegre: FEE.

OMT -ORGANIZAÇÃO MUNDIAL DE TURISMO (2003). Guia de desenvolvimento do turismo sustentável. (Sandra Netz, S, Trad.) Porto Alegre:Bookman, 2003.

Pace, L. A. (2016). How do tourism firms innovate for sustainable energy consumption? A capabilities perspective on the adoption of energy efficiency in tourism accommodation establishments. Journal of Cleaner Production, 111, 409-420.

Peres Junior, M. R., \& de Rezende, D. C. (2011). Gestão da sustentabilidade no segmento hoteleiro: estudo dos meios de hospedagem de Monte Verde, MG. Caderno Virtual de Turismo, 11(2).

Pfitscher, E. D. (2004). Gestão e Sustentabilidade através da contabilidade e controladoria ambiental: estudo de caso na cadeia produtiva de arroz ecológica. (Tese de Doutorado). Universidade Federal de Santa Catarina, Florianópolis.

PNUD. PROGRAMA DAS NAÇÕES UNIDAS PARA O DESENVOLVIMENTO. (2016b). Transformando Nosso Mundo: a Agenda 2030 para o Desenvolvimento Sustentável. Recuperado de http://www.pnud. org.br/Docs/Agenda2030 completo PtBR.pdf. Acesso em: 26 de fevereiro de 2019.

Prud'homme, B. e Raymond, L. (2016). Práticas de desenvolvimento sustentável na indústria da hospitalidade: 
Um estudo empírico do seu impacto na satisfação e intenções do cliente. International Journal of Hospitality Management, 34, 116-126.

Rosa, F. S., \& Silva, L. C. (2017). Sustentabilidade ambiental nos hotéis, contribuição teórica e metodológica. Revista Brasileira de Pesquisa em Turismo, 11(1), 39-60.

Rosalind Jenkins, N., \& Karanikola, I. (2014). Do hotel companies communicate their environmental policies and practices more than independent hotels in Dubai, UAE?. Worldwide Hospitality and Tourism Themes, 6(4), 362-380.

Ruscheinsky, A. (2004). No conflito das interpretações: o enredo da sustentabilidade. Sustentabilidade: uma paixão em movimento. Porto Alegre: Sulina.

Serpa, D. A. F., \& Fourneau, L. F. (2007). Responsabilidade social corporativa: uma investigação sobre a percepção do consumidor. Revista de Administração Contemporânea, 11(3), 83-103.

Tinoco, J. E. P., \& Robles, L. T. (2006). Environmental management accounting and its dimension in business transparency: case study of four Brazilian firms with global activity. Revista de Administração Pública, 40(6), 1077-1096.

Tosun, C. (2001). Challenges of sustainable tourism development in the developing world: the case of Turkey. Tourism management, 22(3), 289-303.

UNITED NATIONS. Sustainable Development Goals: 17 goals to transform our world. 2017.

\section{CONTRIBUIÇÃO DE CADA AUTOR NA ELABORAÇÃO DO ARTIGO:}

JÚLIO CÉSAR FERREIRA: Aplicação da pesquisa e análise dos dados.

GEYSLER ROGIS FLOR BERTOLINI: Orientador da pesquisa.

LORENI TERESINHA BRANDALISE: Revisora da pesquisa. 